\title{
Direct determination of naturally occurring biologically active compound-serum albumin conjugate by matrix-assisted laser desorption/ionization mass spectrometry
}

\author{
H. Tanaka ${ }^{\text {a }}$, L.J. Xuan ${ }^{\text {a }}$, S. Morimoto ${ }^{a}$, Y. Shoyama ${ }^{\mathrm{a}, *}$, R. Isobe ${ }^{\mathrm{b}}$ and K. Nojima ${ }^{\mathrm{c}}$ \\ ${ }^{a}$ Department of Pharmacognosy, Faculty of Pharmaceutical Sciences, Kyushu University, \\ 3-1-1 Maidashi, Higashi-ku, Fukuoka 812, Japan \\ ${ }^{\mathrm{b}}$ Department of Industrial Chemistry, Towa University, 1-1-1 Chikushigaoka, Minami-ku, \\ Fukuoka 815, Japan \\ ${ }^{\mathrm{c}}$ MS Application Laboratory, Application and Research Centre, Analytical Instruments Division, JEOL \\ LTD., 1-2 Musashino, Akisima, Tokyo 196, Japan
}

Received 31 March 2000

Accepted 19 May 2000

\begin{abstract}
Opium alkaloids were conjugated with bovine serum albumin (BSA) to give individual antigen conjugates which were analyzed using BSA as an internal standard by matrix-assisted laser desorption/ionization (MALDI) mass spectrometry. It became clear that 9 molecules of thebaine were conjugated in a thebaine-BSA conjugate. Codeine and morphine contents in individual conjugates were determined to be 12 and 6 molecules, respectively. Using a relative molecular mass of BSA, 11.5 molecules of forskolin conjugated with BSA. Tetrahydrocannabinolic acid (THCA)-carrier protein conjugates using $\beta$-alanine or without $\beta$-alanine as a linker were analyzed. From these results it became evident that the hapten molecules of THCA$\beta$-alanine-BSA, THCA-BSA, THCA- $\beta$-alanine-human serum albumin (HSA) and THCA-HSA were 17.2, 12.7, 27.8 and 54.4 , respectively. Crocin-HSA conjugates were synthesized by two methods using succinate and $\mathrm{NaIO}_{4}$ cleavage of sugar moiety. A broad molecular peak of crocin-HSA conjugate appeared at around $m / z 98,342$ resulting in 30 molecules of crocinhemisuccinate conjugated with HSA. The crocin-HSA synthesized via $\mathrm{NaIO}_{4}$ oxidation showed a sharp molecular peak around 69,504 compared to that of hemisuccinate preparation. The number of crocin combined with HSA was, however, smaller 3.1 molecules.
\end{abstract}

Analysis of monoclonal antibody by MALDI mass spectrometry determined the exact molecular weight and their purities.

\section{Introduction}

Enzyme immunoassay systems using monoclonal antibodies (MAb) have become an important methodology for studies on receptor binding analysis and the quantitative and qualitative analysis of drugs and naturally occurring biologically active compounds [1]. For the formation of antibodies against compounds of low molecular mass, the synthesis of hapten-carrier protein conjugates is necessary. Usually the specificity of an immunoassay method is dependent on the site of linkage between the hapten and protein moieties, and also the number of haptens in the immunogen conjugate. However, there are

\footnotetext{
*Corresponding author. Tel.: +8192 642 6580; Fax: +8192642 6545; E-mail: shoyama@ shoyaku.phar.kyushu-u.ac.jp.
} 
no direct and appropriate analytical methods for synthetic hapten-carrier polymer conjugates without involving differential UV spectrophotometric, radioactive or chemical methods. Wangats et al. [2] determined the hapten density of immunoconjugates by MALDI mass spectrometry. We also established the direct analytical methods for hapten-carrier protein conjugates using an internal standard by MALDI mass spectrometry [3-5]. The determination method of antigen conjugates having lower molecular compound, and the purity of MAb prepared after immunization with synthetic hapten-carrier protein conjugates will be also discussed in this chapter.

\section{Analysis of opium alkaloid-bovine serum albumin (BSA) conjugate by MALDI mass spectrometry}

Since major opium alkaloids, morphine (1), codeine (2) and thebaine (3), are well-known for their importance not only as therapeutic drugs but also as synthetic resources, a highly sensitive and reproducible analytical methodology is needed in the fields of medicine and plant biotechnology. Among them the formation of anti-morphine MAb has been investigated for the determination of binding site, the specificity of binding and the immunochemical analysis [6-12]. However, since no report on the anti-codeine and thebaine MAbs has been presented, we have synthesized hapten-BSA conjugates as an antigen, and determined the exact number of hapten by MALDI mass spectrometry in this section.

\subsection{Materials and methods}

\subsubsection{Synthesis of hapten-carrier protein conjugate}

A $0.1 \mathrm{mmol}$ of $\mathrm{N}$-(2-carboxyethyl)-northebaine was treated with $0.905 \mu \mathrm{mol} \mathrm{BSA}$ as reported previously [13] with some modification, and then dialyzed against $\mathrm{H}_{2} \mathrm{O}$ to give morphine-BSA (4) conjugates. Codeine- (5) and thebaine-BSA (6) conjugates were synthesized in the same manner.

\subsubsection{MALDI mass spectrometry}

A small amount (1-10 pmol) of the antigen conjugate was mixed with BSA (1-10 pmol) and a $10^{3}$-fold molar excess of sinapinic acid in an aqueous solution containing $10 \%$ trifluoroacetic acid. The mixture was placed inside a JMS-1D11700 Time-of-Flight (TOF) mass monitor and irradiated with a $\mathrm{N}_{2}$ laser $(337 \mathrm{~nm}, 3 \mathrm{~ns}$ pulse). The ions formed by each pulse were accelerated by a $30-\mathrm{kV}$ potential into a $1.7-\mathrm{m}$ evacuated tube and detected using an IBM PC compatible computer [3-5].

\subsubsection{Immunization and hybridization}

BALB/C male mice were injected intraperitoneally with opium alkaloids (1, 2 and 3 , respectively)BSA dissolved in phosphate buffered saline three times $(50 \mu \mathrm{g}$ of protein in each injection) every 2 week (the first immunization was injected as a 1:1 emulsion in Freund's complete adjuvant). On the third day after the final immunization, splenocytes were isolated and fused with a HAT-sensitive mouse myeloma cell line, P3-X63-Ag8-U1 cells, by the polyethylene glycol method. Hybridomas producing $\mathrm{MAb}$ reactive to individual opium alkaloids were cloned by the limited dilution method as previously reported [14].

\subsection{Results and discussion}

Figure 1 indicates the structures of $\mathbf{1}, \mathbf{2}$ and $\mathbf{3}$. It seems to be that the synthetic pathway of $\mathbf{4}$ using succinic acid as a linker is easier because no need any reaction. However, since the cross-reaction is 


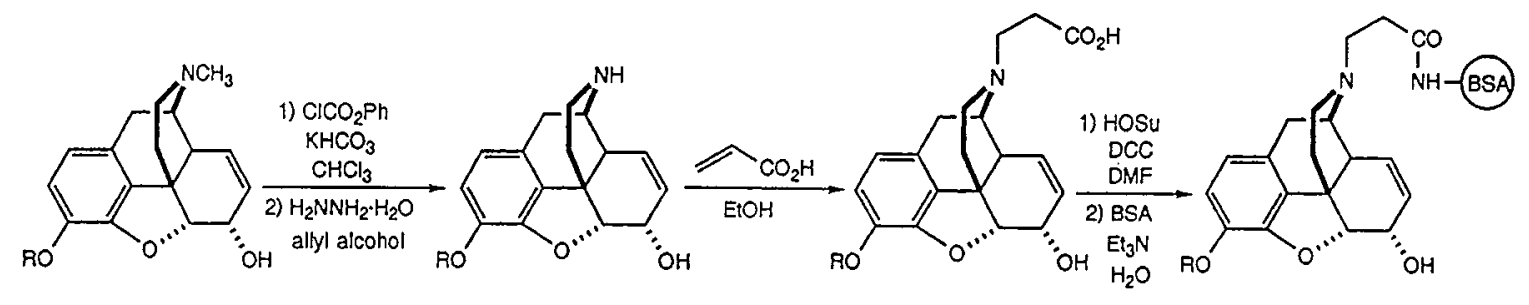

morphine, $\mathrm{R}=\mathrm{H}(1)$

codeine, $\mathrm{R}=\mathrm{CH}_{3}(2)$

morphine-BSA conjugate, $\mathrm{R}=\mathrm{H}(4)$ codeine-BSA conjugate, $\mathrm{R}=\mathrm{CH}_{3}(5)$

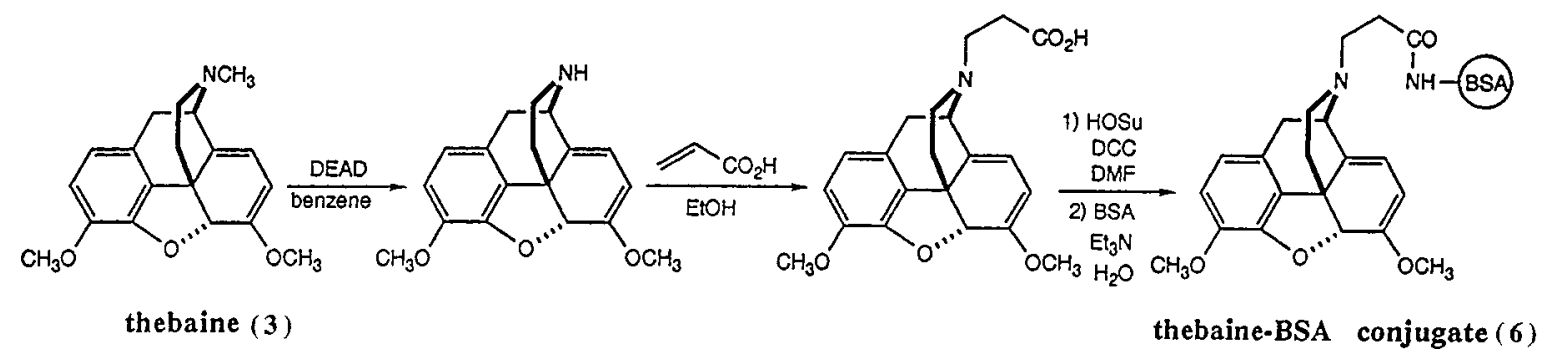

Fig. 1. Synthetic pathway of opium alkaloid-bovine serum albumin conjugate.

mostly important in our study, the structural circumstances around hydroxyl group or methoxyl group in a molecule might be important. Moreover, $\mathbf{3}$ has no hydroxyl group. Therefore, we select the synthetic pathway of opium alkaloids-BSA conjugate via N-(2-carboxyethyl)-nor alkaloids as indicated in Fig. 1.

Figure 2A shows the MALDI co-mass spectra of $\mathbf{6}$ and BSA used as an internal standard. In MALDI mass spectrometry, the matrix plays a key role in the ionization process. For this application, we selected sinapinic acid matrix that was commonly used for proteins over MW 10,000. It indicates the singly, doubly, and triply ionized molecular ions of the intact conjugate. The small peak at $m / z 66,869$ is $[\mathrm{M}+\mathrm{H}]^{+}$of BSA, which was not observed in the absence of the internal standard BSA, excluding the possible existence of noncovalent conjugates in the sample. The higher $[\mathrm{M}+\mathrm{H}]^{+}$peak of 6 is 70,048, indicating that the calculated molecular weight of $\mathbf{6}$ is 69,417 using a calculated molecular weight of 66,267 for BSA; this difference is 3,150 . Since the calculated molecular weight of the thebaine moiety is 352 , this difference corresponds to 9 molecules of $\mathbf{3}$ combined with BSA, as shown in Table 1.

The number of moles of hapten in $\mathbf{5}$ was also determined to be 12 (Table 1, Fig. 2B). Since the $[\mathrm{M}+\mathrm{H}]^{+}$peak of $\mathbf{4}$ overlapped that of BSA, these were analyzed separately, resulting in 6 molecules of 1 conjugated with BSA (Table 1). Conjugate 4 gives a broad peak, as indicated in Fig. 2C, suggesting that the conjugate is a mixture of the conjugates consisting of around 6 molecules of $\mathbf{1}$. Although no differences on the ability to conjugate for individual alkaloids with BSA may be expected, the hapten number of conjugates is different individually, for reasons which are still obscure.

Suitability of hapten-BSA conjugate on 1, $\mathbf{2}$ and $\mathbf{3}$ was confirmed by producing MAb against individual alkaloids resulting in the higher sensitivity and the small cross-reactivity as indicated in Table 2 [14]. 


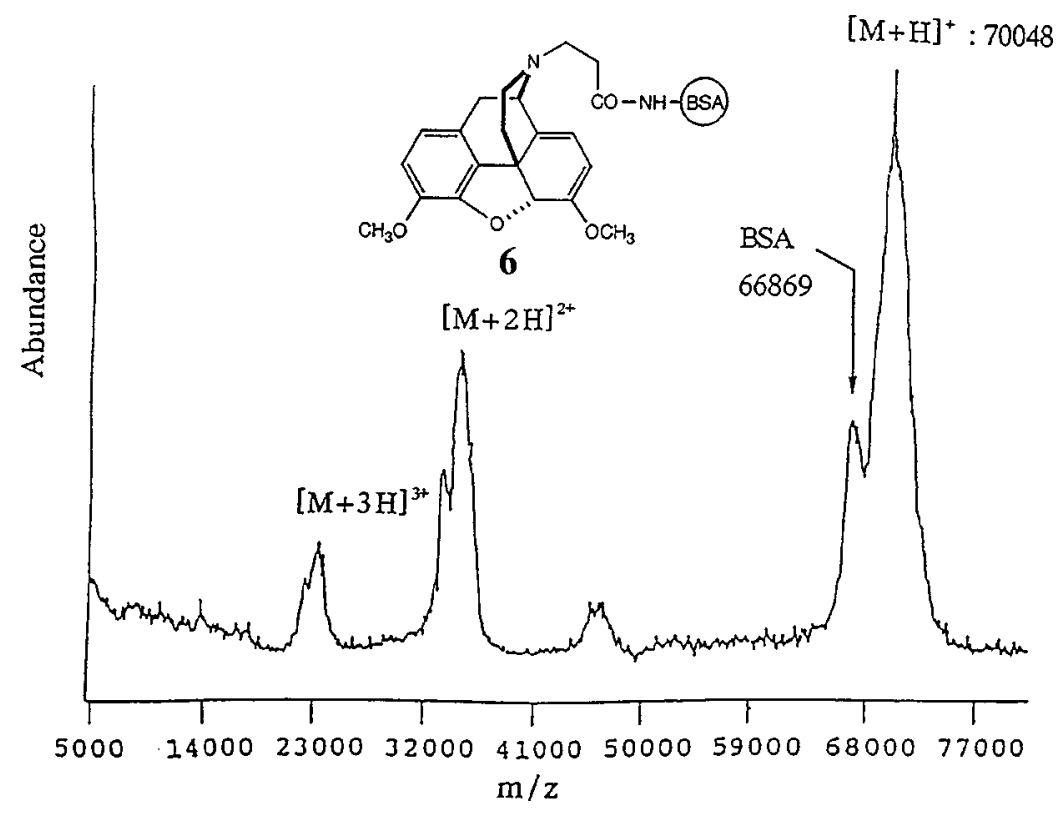

(A)
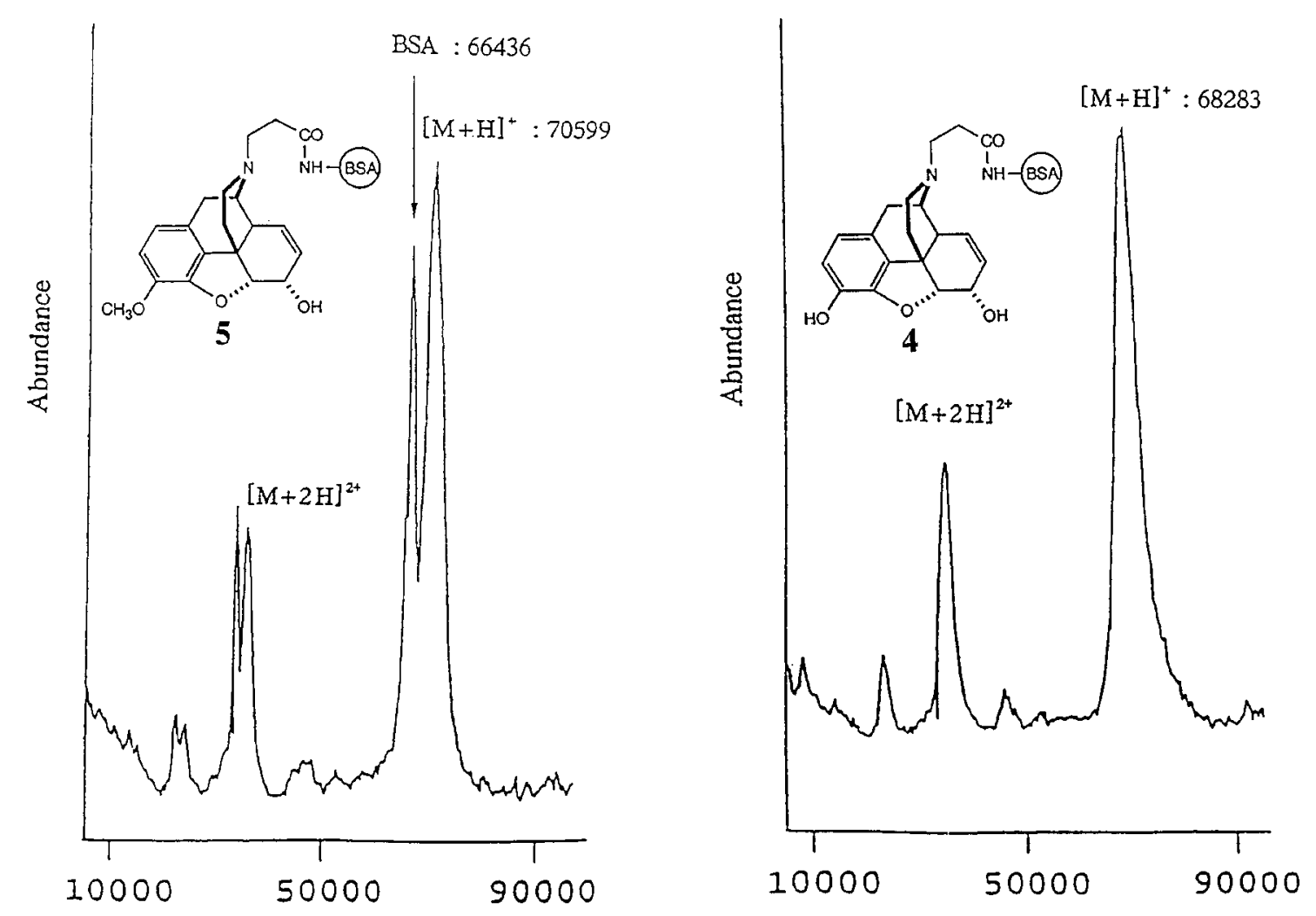

(B)

$\mathrm{m} / \mathrm{z}$

(C)

$\mathrm{m} / \mathrm{z}$

Fig. 2. MALDI mass spectra of opium alkaloid-bovine serum albumin conjugate. (A) $\mathbf{6}$ and BSA added as an internal standard; (B) 5 and BSA added as an internal standard; (C) 4. 
Table 1

Hapten number in opium alkaloid conjugates combined with bovine serum albumin

\begin{tabular}{lccc}
\hline & Thebaine-BSA & Codeine-BSA & Morphine-BSA \\
\hline MW of hapten & 352 & 341 & 326 \\
Calcd.MW. & $69417 \pm 162$ & $70419 \pm 148$ & $68283 \pm 56$ \\
(c.v. $\%)$ & $(n=3,0.23)$ & $(n=3,0.21)$ & $(n=3,0.08)$ \\
No. of hapten & 9 & 12 & 6 \\
\hline
\end{tabular}

* Coefficient of variation.

Table 2

Cross-reactivities (\%) in individual opium alkaloid

\begin{tabular}{lcc}
\hline Compound & Anti-codeine MAb & Anti-thebaine MAb \\
\hline Morphine & 2.97 & 0 \\
Codeine & 100 & 0.04 \\
Thebaine & 5.96 & 100 \\
\hline
\end{tabular}

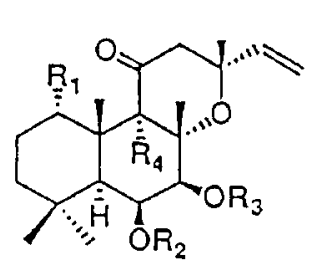

$\begin{array}{llll}R_{1} & R_{2} & R_{3} & R_{4}\end{array}$

$\mathrm{OH} \quad \mathrm{H} \quad \mathrm{AC} \mathrm{OH}$

$\mathrm{H} \quad \mathrm{H}$ AC $\mathrm{OH}$

$\mathrm{H} \quad \mathrm{H}$ AC $\mathrm{H}$

$\mathrm{OH}$ AC $\mathrm{H} \quad \mathrm{OH}$

$\mathrm{OH} H \quad \mathrm{H} H$

\begin{tabular}{ll}
\hline Analogs & Cross reactivity $(\%)$ \\
\hline 1-DF & 0.63 \\
1,9-DDF & 1.30 \\
6-A-7-DF & 1.13 \\
7-DF & 5.57 \\
PS-3 & 0 \\
PS-4 & 0 \\
PS-7 & 0 \\
\hline
\end{tabular}

forskolin (7)

$$
\text { 1-deoxyforskolin(1-DF) (8) }
$$

1,9-dide oxyforskolin(1,9-DDF) (9) 6-acetyl-7-deacetylforskolin(6-A-7DF) (10)

\section{7-deacetylforskolin(7-DF)( 11 )}

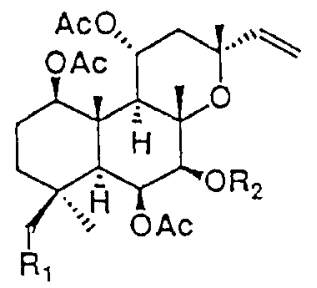

$\begin{array}{lll}R_{1} & R_{2} & \\ H & H & P S-3 \\ H & \text { AC } & \text { PS -4 } \\ \text { OH } & H & \text { PS -7 }\end{array}$

Fig. 3. Structures of $\mathbf{7}$ and its analogs, and cross-reactions against its analogs.

\section{Analysis of forskolin-BSA conjugate by MALDI mass spectrometry}

Forskolin (7), a labdane diterpenoid, was isolated from the roots of Coleus forskohlii Briq. (Lamiaceae) [15] as an activator of adenylate cyclase [16], leading to an increase of c-AMP, used widely as an important reagent and as a drug in Germany, India and Japan. For production of MAb, the synthesis of hapten which is derived from immuno antigen and linker bridge, and carrier protein conjugates is necessary. In this case succinic acid was used as a linker because the acetyl group at C-7 position in $\mathbf{7}$ is specifically cleavaged to give 7-deacetylforskolin (11) as indicated in Fig. 3. Therefore, hapten, 7-deacetylforskolin 7-semisuccinyl residue was synthesized from $\mathbf{1 1}$ after deacetylation of $\mathbf{7}$ followed to synthesize forskolin-BSA conjugate (12) as an antigen. 


\subsection{Materials and methods}

\subsubsection{Materials}

Compound 7 was isolated from the tuberous roots of Coleus forskohlii Briq. regenerated from tissue culture in this laboratory as previously reported manner [15].

\subsubsection{Synthesis of antigen conjugates}

7-Deacetylforskolin 7-semisuccinate was synthesized by the same method as previously reported [17], and identified by ${ }^{1} \mathrm{H}$ NMR and ${ }^{13} \mathrm{C}$ NMR compared with the data of previous report [17].

To a solution of 7-deacetyl-7-hemisuccinyl forskolin $(18.3 \mathrm{mg})$ in dry dioxane $(136.5 \mathrm{ml})$ were added 1-ethyl-3-(3-dimethylaminopropyl)-carbodiimide (EDC) $(10.5 \mathrm{mg}$ ) and $\mathrm{N}$-hydroxysuccinimide (HSM) (6.3 mg), and the mixture was stirred at room temperature for $2 \mathrm{hr}$. After addition of $\mathrm{H}_{2} \mathrm{O}$ the reaction mixture was evaporated in vacuo. The residue was purified by $\mathrm{SiO}_{2}$ column chromatography eluting with $\mathrm{CHCl}_{3}-\mathrm{MeOH}(20: 1$, containing $0.2 \%$ acetic acid) to give activated 7-deacetylforskolin-7-hemisuccinyl ester $(18.5 \mathrm{mg})$.

BSA $(43.9 \mathrm{mg})$ was dissolved in $\mathrm{H}_{2} \mathrm{O}(800 \mu \mathrm{l})$ containing triethylamine $\left(\mathrm{Et}_{3} \mathrm{~N}\right)(8.8 \mu \mathrm{l})$. To this solution, the synthetic activated ester described above $(18.5 \mathrm{mg}$ ) in dimethylformamide (DMF; $400 \mu \mathrm{l})$ was added at $5^{\circ} \mathrm{C}$, and kept at $5^{\circ} \mathrm{C}$ under $\mathrm{N}_{2}$ for $24 \mathrm{hr}$. The solution was dialyzed against $\mathrm{H}_{2} \mathrm{O}$ overnight, and then lyophilized to give $\mathbf{1 2}(51.5 \mathrm{mg})$. Forskolin-HSA conjugate was also synthesized using the same method to that for $\mathbf{1 2}$.

\subsubsection{Analysis of forskolin-BSA conjugate by MALDI mass spectrometry}

MALDI mass spectrometry analysis was investigated in the same manner with that of opium alkaloids as indicated above and previously reported [3].

\subsubsection{Immunization and hybridization}

Immunization and hybridization were done in the same manner with that of opium alkaloids as indicated in Section 2 and previously communicated [18].

\subsection{Results and discussions}

Figure 4 shows the co-mass spectra of the antigen conjugate of $\mathbf{7}$ and BSA which was added as an internal standard. The relative molecular mass of BSA was 66,928 (average for triplicates, c.v. 0.09\%) in agreement with a previous report of which the calculated relative molecular mass of BSA was 66,267. Figure 4 also shows only the singly, doubly, and triply protonated molecules of the intact conjugate which can be used for determination of the molecular mass of the hapten conjugate. Fragmentation is not an artifact of the ionization technique. A sharp peak coinciding with the conjugate appeared at $m / z 72,160$ (average for triplicates, c.v. 0.049\%) resulting in the calculated relative molecular mass of 71,447. Using a relative molecular mass of 66,267 for BSA, the calculated mass of hapten, the 7-deacetylforskolin 7semisuccinyl residues (molecular weight; 451), is 5,180 indicating 11.5 molecules of 7 conjugated with BSA.

In order to confirm the antigen conjugate formation, mice splenocytes immunized with the antigen conjugate of $\mathbf{7}$ and myeloma cells were fused to make hybridoma, by the polyethylene glycol method. Anti-forskolin antibody formation was confirmed by enzyme linked immuno-sorbent assay (ELISA) as in a previous report $[18,19]$. Anti-forskolin antibodies appear to be of satisfactory affinity and specificity. The reactivities of immunoglobulin type MAb against 7 were investigated resulting in different affinities as shown in the previous paper [18]. Cross reactivities determined using forskolin analogs were indicated 


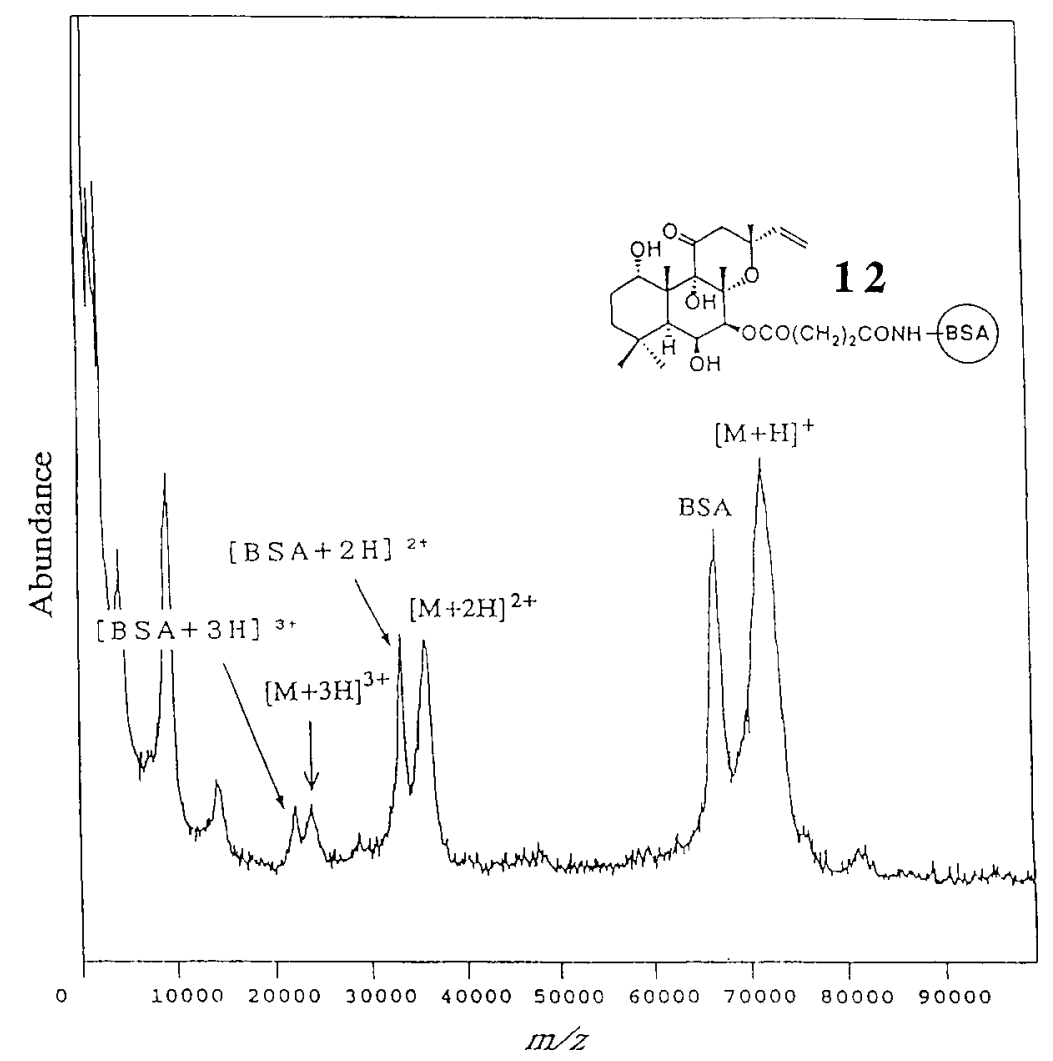

Fig. 4. MALDI mass spectrometry of $\mathbf{1 2}$ and bovine serum albumin added as an internal standard.

in Fig. 3. From these results it becomes evident that 7 was correctly conjugated with BSA in the antigen conjugate.

\section{Analysis of THCA-albumin conjugate by MALDI mass spectrometry}

Since a receptor for the most pharmacologically active cannabinoid, tetrahydrocannabinol (THC) (Fig. 5) [20], and an endogenous ligand (anandamide) for its receptor were found [21], cannabinoids including THC have attracted interest as resources of drugs. Tetrahydrocannabinolic acid (THCA) (13) is a genuine cannabinoid of THC contained in fresh Cannabis plant [22]. In continuing studies on marihuana, we have examined the facilitating effects of THC on the rise in intrasynaptosomal $\mathrm{Ca}^{++}$concentration [23], biotransformation of cannabinoids using plant tissue culture [24] and the purification of biosynthetic enzymes catalyzing the transformation of cannabigerolic acid (CBGA) (18) to cannabidiolic acid (CBDA) (16) [25] or to 13 [26], respectively. Thereafter, we planned to prepare anti-THCA MAb for ELISAs in the biological studies of cannabinoids, and for the determination procedure of marihuana samples in the field of forensic sciences. Here we report a method for the determination of hapten-carrier protein conjugates of $\mathbf{1 3}$ by MALDI mass spectrometry and the formation of antibody in the context of the marihuana project. 
<smiles>CC1=CC2c3c(cc(O)c(C(=O)O)c3O)OC(C)(C)[C@H]2CC1</smiles>

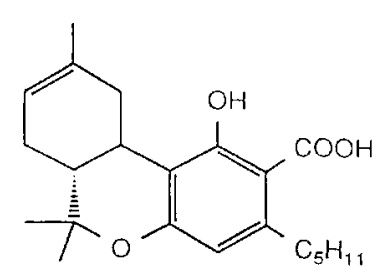

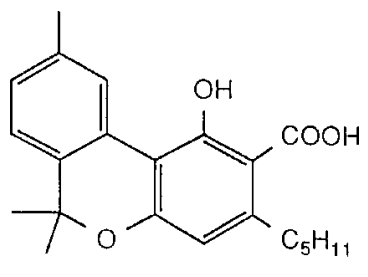

$\Delta^{1}-$ THCA $(100 \%)(13)$ $\triangle^{6}-$ THCA $(55 \%)(14)$

CBNA (174\%)(15)<smiles>C=C(C)[C@H]1CCC(C)=CC1c1c(O)cc(CC)c(P)c1O</smiles>
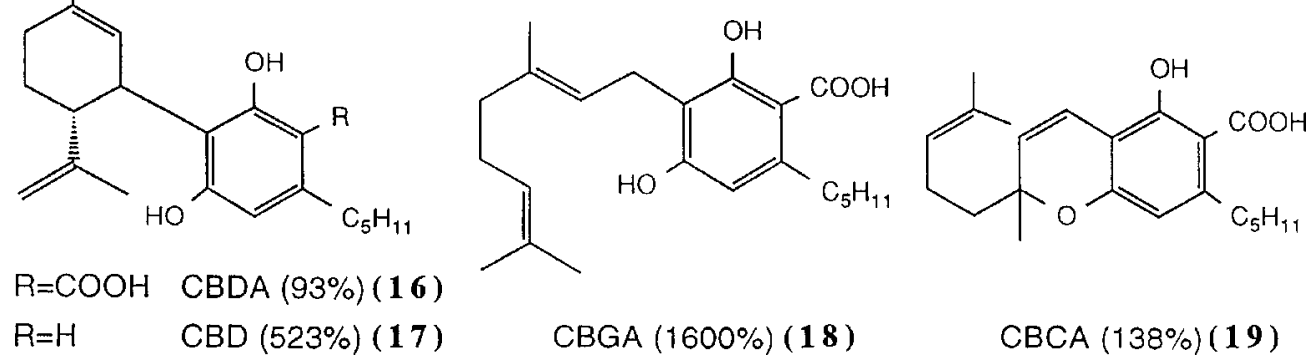

Fig. 5. Structures of cannabinoids and their cross-reactions (\%) for anti-tetrahydrocannabinolic acid monoclonal antibody.

\subsection{Materials and methods}

\subsubsection{Chemicals and reagents}

Compound $\mathbf{1 3}$ was isolated from dried Cannabis leaves (Mexican strain) in this laboratory as described previously [22].

\subsubsection{Synthesis of haptens}

Compound 13 (570 mg) was dissolved in a solution of dicyclohexylcarbodiimide (DCC) $(576 \mathrm{mg})$ and succinic acid $(240 \mathrm{mg})$ in dimethylformamide (DMF) $(4 \mathrm{ml})$ and allowed to stand at room temperature for $2 \mathrm{hr}$. To the reaction mixture $\mathrm{H}_{2} \mathrm{O}(100 \mu \mathrm{l})$ was added and the mixture was centrifuged $(2,000 \mathrm{rpm})$ for $10 \mathrm{~min}$. The supernatant was evaporated to dryness in vacuo and then purified by $\mathrm{SiO}_{2}$ column chromatography using hexane-ethyl acetate $(5: 1)$ as eluent to give THCA HSM (20) $(410 \mathrm{mg})$ [5]. The structure was confirmed by fast atom bombardment (FAB) mass spectrum, ${ }^{1} \mathrm{H}$ and ${ }^{13} \mathrm{C}$ NMR spectrometries [5].

A $36 \mu$ mol amount of $\mathbf{2 0}$ was treated with $0.61 \mu \mathrm{mol}$ of BSA as reported previously with some modification, and then dialyzed against $\mathrm{H}_{2} \mathrm{O}$ to give THCA-BSA conjugate (23) as indicated in Table 3 [5] .

Borate buffer solution ( $\mathrm{pH} \mathrm{10}$ ) (4 ml) of $\beta$-alanine ( $360 \mathrm{mg}$ ) was mixed with a dioxane solution (12 ml) of $20(360 \mathrm{mg})$ and then allowed to stand at room temperature for $3 \mathrm{hr}$. The reaction mixture was evaporated in vacuo. The residue was purified by $\mathrm{SiO}_{2}$ column chromatography to give $\mathrm{N}-\mathrm{THCA}-\beta$-alanine (21) $\left(60 \mathrm{mg}\right.$ ). Structure of this product was determined by FAB mass spectrum, ${ }^{1} \mathrm{H}$ NMR and ${ }^{13} \mathrm{C}$ NMR spectrometries as previously reported [5].

Compound $21(13.1 \mathrm{mg})$ was dissolved in dioxane $(1.13 \mathrm{ml})$ and tri-N-butylamine $(9 \mu \mathrm{l})$ and isobutyl chloroformate $(6.4 \mu \mathrm{l})$ were added. After stirring of the mixture for $20 \mathrm{hr}$, BSA dissolved in $25 \mathrm{mM}$ borate buffer ( $\mathrm{pH} \mathrm{10})(1.7 \mathrm{ml})$ and dioxane $(0.58 \mathrm{ml})$ was added dropwise. The mixture was stirred at $4{ }^{\circ} \mathrm{C}$ for 3 days and then dialyzed against $\mathrm{H}_{2} \mathrm{O}$ to give THCA- $\beta$-alanine-BSA conjugates (22) as indicated in Table 3 [5]. 
Table 3

\begin{tabular}{lcccc}
\multicolumn{5}{c}{ Hapten number in tetrahydrocannabinolic acid-carrier protein conjugates } \\
\hline Antigen & $\begin{array}{c}\text { THCA- } \beta- \\
\text { Ala-BSA }\end{array}$ & THCA-BSA & THCA- $\beta-$ & THCA-HSA \\
& \multicolumn{4}{c}{ Mixed anhydride method } \\
\cline { 2 - 5 } & 0.39 & 0.61 & 0.57 & DCC method \\
\hline Used protein $(\mu \mathrm{mol})$ & 20.7 & 36 & 23 & 0.45 \\
Used hapten $(\mu \mathrm{mol})$ & $(429)$ & $(358)$ & $(429)$ & 279 \\
(M.W.) & $73549 \pm 175$ & $70792 \pm 59$ & $78097 \pm 222$ & $85219 \pm 107$ \\
Calcd. M. W. & $(n=4,0.238)$ & $(n=4,0.083)$ & $(n=4,0.284)$ & $(n=4,0.126)$ \\
(c.v. \% $)^{*}$ & 17.2 & 12.7 & 27.8 & 54.4 \\
No. of hapten & \multicolumn{4}{c}{} \\
\hline
\end{tabular}

${ }^{*}$ Coefficient of variation.

THCA-HSA (24) and THCA- $\beta$-alanine-HSA (25) were synthesized in the same manner with that of 23 (Table 3) [5].

\subsubsection{Analysis by MALDI mass spectrometry}

MALDI mass spectrometry analysis was investigated in the same method with that of opium alkaloids as indicated above Section 2 and previously reported [5].

\subsubsection{Immunization and hybridization}

Immunization and hybridization were done in the same manner with that of opium alkaloids as indicated in Section 2 and previously communicated [27].

\subsection{Results and discussions}

The synthetic pathway of $\mathbf{2 2}$ is shown in Fig. 6. The structure of the individual intermediate was confirmed by the FAB mass, ${ }^{1} \mathrm{H}$ NMR and ${ }^{13} \mathrm{C}$ NMR spectra, respectively, [5].

In order to confirm the purity of the synthesized antigen conjugate, a small amount of $\mathbf{2 3}$ was mixed with a $10^{3}$-fold molar excess of sinapinic acid in an aqueous solution containing trifluoroacetic acid and analyzed by MALDI mass spectrometry. A sharp $[\mathrm{M}+\mathrm{H}]^{+}$peak of $\mathbf{2 3}$ appeared at $m / z$ 70,792 together with singly, doubly and triply ionized molecule ions of the intact conjugate as shown in Fig. 7. From the spectrum it is suggested that the conjugate is highly purified and can be used for the determination of THCA molecules.

As reported previously, the antigen conjugated for $\mathbf{7}$ has been confirmed more precisely by MALDI mass spectrometry using an internal standard. Therefore, BSA or HSA was used as an internal standard in this study. Figure 7 shows the MALDI mass spectrum of $\mathbf{2 3}$ and BSA used as an internal standard. This shows only the singly, doubly and triply ionized molecule ions of the intact conjugate. The sharp peak at $m / z 66,465$ is $[\mathbf{M}+\mathbf{H}]^{+}$of BSA. A small $[\mathbf{M}+\mathbf{H}]^{+}$peak of $\mathbf{2 3}$ is at $m / z 70,792$, indicating that the calculated molecular mass of $\mathbf{2 3}$ is 70,581 using a calculated molecular mass of 66,267 for BSA. The calculated molecular mass of the THCA moiety (MW 341) is 4,314. From this result, 12.7 molecules of THCA combined with BSA as indicated in Table 3. Moreover, the coefficient of variation of $\mathbf{2 3}$ is fairly low, $0.083 \%(n=4)$, as indicated in Table 3 . Therefore, this method is suitable too for the determination of phenolic compound-carrier protein conjugates.

Figure 8 shows the MALDI mass spectrum of 22 and BSA used as an internal standard, and indicates the singly, doubly and triply ionized molecule ions of the conjugate like 22 shown in Fig. 8. The calculated molecular mass of the THCA- $\beta$-alanine moiety (MW 412) is 7,064 (see Table 3). From these 


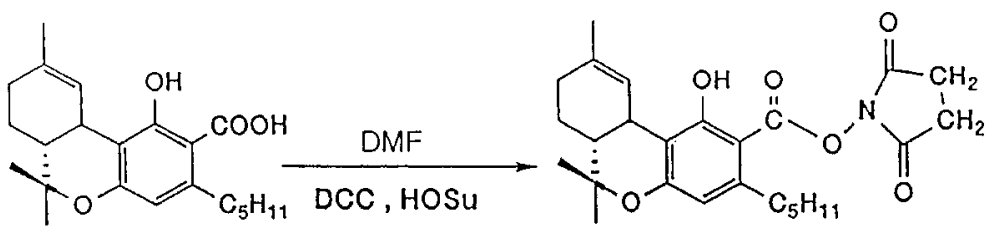

THCA(13)

N-hydroxysuccinimide ester $(20)$

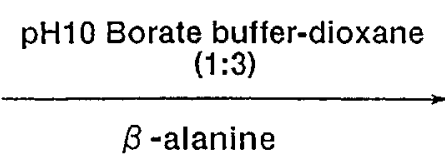<smiles>CC1=CC2c3c(cc(O)c(C(=O)NCCC(=O)O)c3O)OC(C)(C)C2CC1</smiles>

THCA- $\beta$-alanine ( 21 )

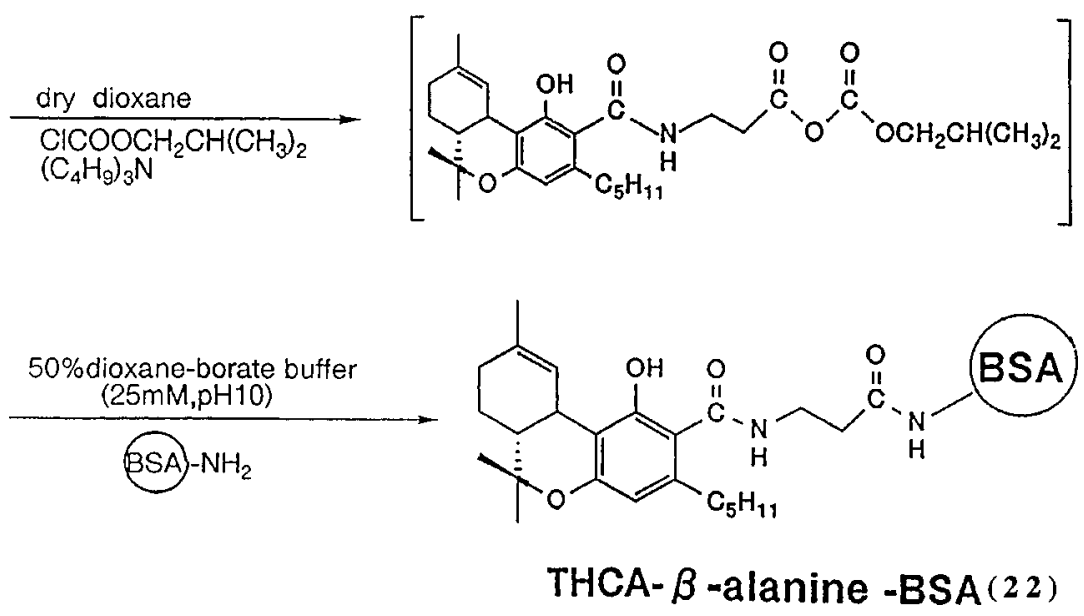

Fig. 6. Synthetic pathway of 22.

results, 17.2 molecules of THCA- $\beta$-alanine moiety combined with BSA. The $[\mathrm{M}+\mathrm{H}]^{+}$peak of $\mathbf{2 2}$ is broader than those of BSA or $\mathbf{2 3}$. This suggests that $\mathbf{2 2}$ might be complexes combined with different numbers of haptens.

The $[\mathrm{M}+\mathrm{H}]^{+}$peak of $\mathbf{2 4}$ conjugate indicated in Fig. 9 appears at $m / z$ 84,897, suggesting that larger amounts of $\mathbf{1 3}$ may combine with HSA compared with that of $\mathbf{2 3}$ (Fig. 9). The number of haptens of $\mathbf{2 4}$ was determined to be 54.4 (Table 3) as calculated for $\mathbf{2 3}$. The reason why so many THCA hapten molecules combined with HSA may be due to the 10-fold use of THCA hapten (279 mol; Table 3). In this case the conjugation of THCA hapten with HSA occurred almost completely since 59 molecules of lysine are contained in HSA.

The $[\mathrm{M}+\mathrm{H}]^{+}$peak of $\mathbf{2 5}$ conjugate was at $m / z$ 78,097 (Fig. 10). The number of haptens of $\mathbf{2 5}$ was determined to be 27.8 (Table 3) as calculated for $\mathbf{2 4}$. Conjugate $\mathbf{2 5}$ gives a broad peak as shown in Fig. 10, suggesting that the conjugate is a mixture consisting of around 25-31 molecules of hapten. Although no differences in conjugation ability of individual haptens with BSA or HSA may be expected, the hapten numbers in the conjugates differ individually. The reason is obscure. 


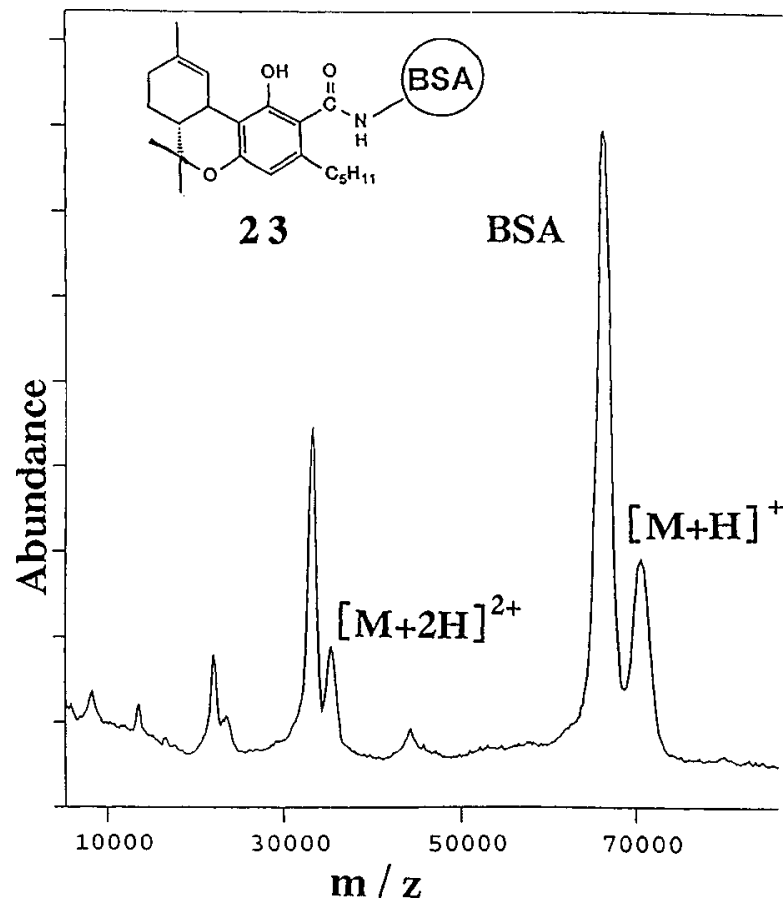

Fig. 7. MALDI mass spectrometry of $\mathbf{2 3}$ and bovine serum albumin added as an internal standard.

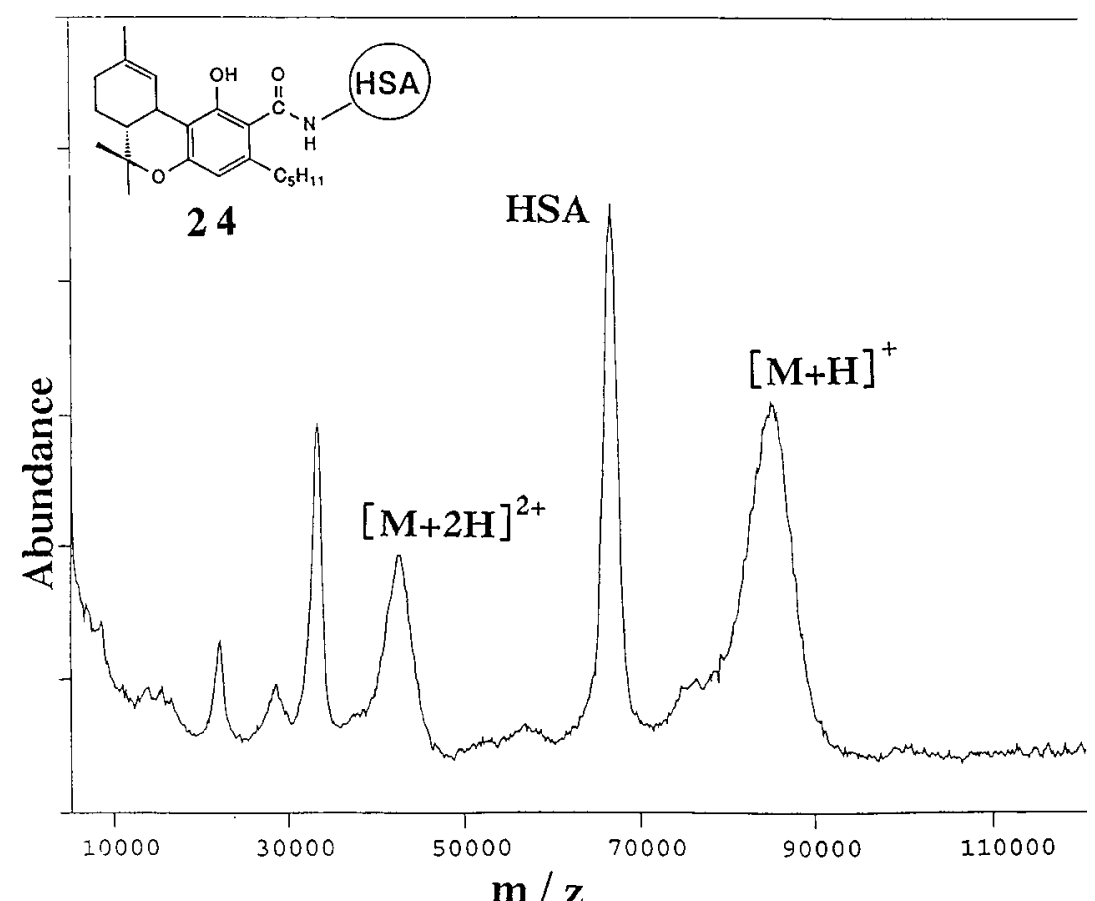

Fig. 8. MALDI mass spectrometry of $\mathbf{2 4}$ and human serum albumin added as an internal standard. 


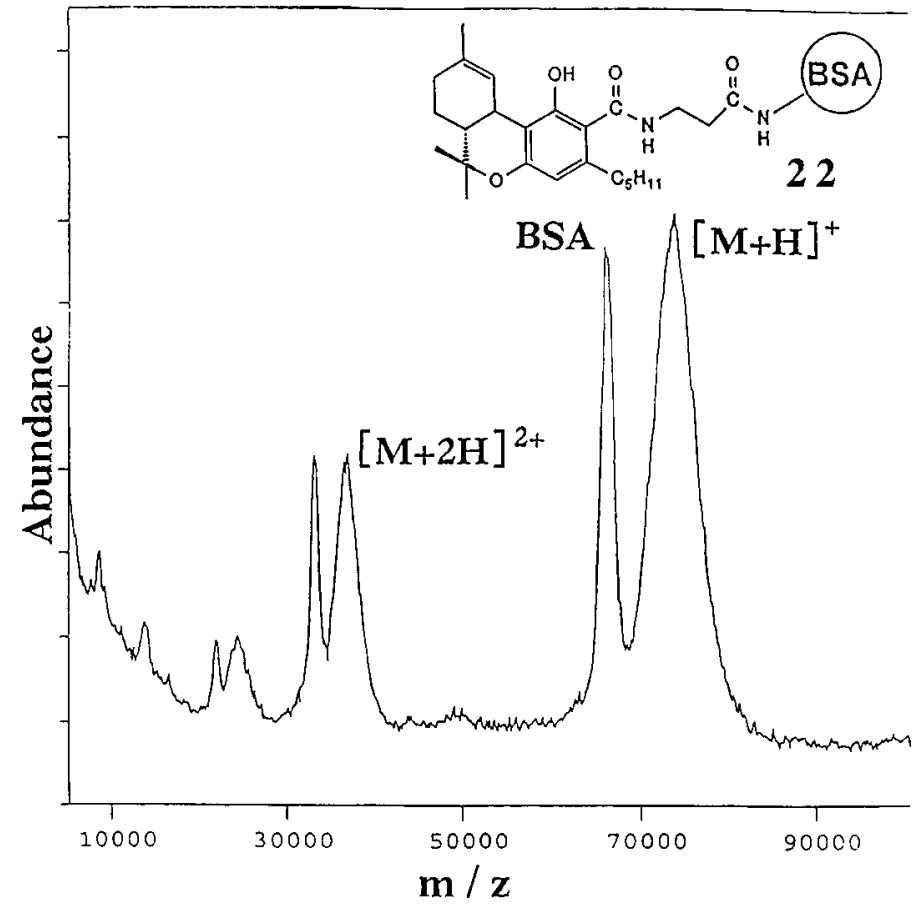

Fig. 9. MALDI mass spectrometry of $\mathbf{2 2}$ and bovine serum albumin added as an internal standard.

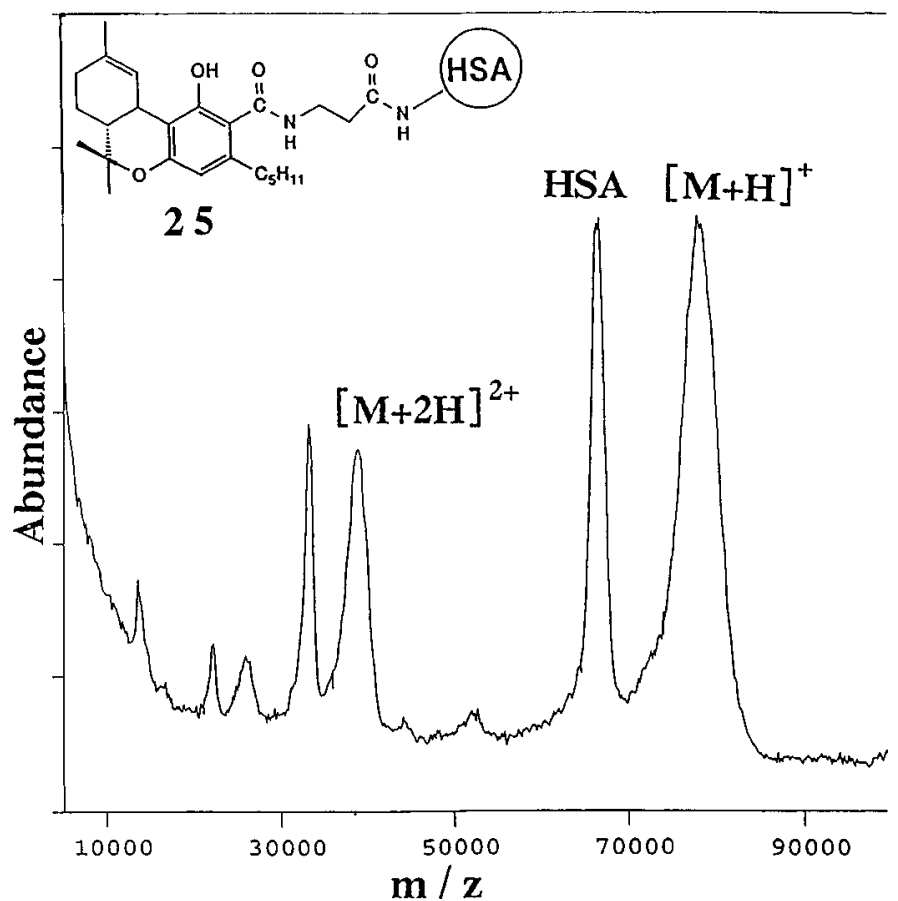

Fig. 10. MALDI mass spectrometry of $\mathbf{2 5}$ and human serum albumin added as an internal standard. 
Wide cross reactivities of anti-THCA MAb against various cannabinoids were observed as indicated in Fig. 5.

\section{Analysis of crocin-carrier protein conjugate by MALDI mass spectrometry}

Crocus sativus L. has been used in Chinese traditional medicine for its anodyne, tranquid and emmenagogue properties. We have recently found that an ethanol extract of $C$. sativus L. improved the impairment of memory acquisition in $30 \%$ ethanol-treated mice in passive avoidance learning tasks [28, 29], suggesting that it has an ameliorating effect on the ethanol-induced impairment of learning and memory. Moreover, the effects of ethanol and crocin (26) on the induction of long-term potentiation (LTP) were investigated in the CA1 region of rat hippocampal slices in vitro indicating that crocin significantly prevented the LTP-suppressing action of ethanol [30-32]. It is suggested that the receptor for crocin exists in the mice brain, therefore the preparation of anti-crocin MAb has been investigated in order to confirm its existence and its distribution. For this purpose the conjugate of crocin and carrier protein was prepared and analyzed the number of hapten by MALDI mass spectrometry.

\subsection{Materials and methods}

\subsubsection{Material}

Compound 26 was isolated from the $50 \%$ ethanol extracts of stigmas of $C$. sativus $\mathrm{L}$. in this laboratory as previously reported [33].

\subsubsection{Synthesis of crocin-carrier protein conjugates}

Compound 26 (5 mg) dissolved in $\mathrm{H}_{2} \mathrm{O}(1 \mathrm{ml})$ was added to a solution of $\mathrm{NaIO}_{4}(2 \mathrm{mg})$ in $\mathrm{H}_{2} \mathrm{O}(500 \mu \mathrm{l})$ dropwisely, then stirred at room temperature for $1 \mathrm{hr}$. A solution of HSA $(6 \mathrm{mg})$ in $50 \mathrm{mM}$ carbonate buffer $(500 \mu \mathrm{l}, \mathrm{pH}$ 9.6) was added and stirred at room temperature for $5 \mathrm{hr}$. The reaction mixture was dialyzed against $\mathrm{H}_{2} \mathrm{O}$ overnight, changing the $\mathrm{H}_{2} \mathrm{O}$ for several times. A milky solution was obtained. After lyophilization crocin-HSA conjugate (31) $(5 \mathrm{mg})$ was afforded.

Crocin hemisuccinate (27) was synthesized by the same manner with that of forskolin as described above with modification. The structure was confirmed by FAB mass, ${ }^{1} \mathrm{H}$ NMR and ${ }^{13} \mathrm{C}$ NMR. $27(15 \mathrm{mg})$, EDC $(3 \mathrm{mg})$ and HOSu $(4.5 \mathrm{mg})$ were dissolved in anhydrous DMF $(500 \mu \mathrm{l})$ and kept at $4{ }^{\circ} \mathrm{C}$ overnight. The reaction was ended by an addition of $\mathrm{H}_{2} \mathrm{O}(100 \mu \mathrm{l})$, and the solution was immediately added to a solution of BSA $(15.6 \mathrm{mg})$ in $\mathrm{H}_{2} \mathrm{O}(500 \mu \mathrm{l})$ and $\mathrm{Et}_{3} \mathrm{~N}(5 \mu \mathrm{l})$. After stirring at $4^{\circ} \mathrm{C}$ for $24 \mathrm{hr}$, the reaction solution was dialyzed against $\mathrm{H}_{2} \mathrm{O}$ overnight, changing $\mathrm{H}_{2} \mathrm{O}$ for several times, lyophilizing to give crocin hemisuccinate BSA conjugate (29) (22 mg).

\subsubsection{Analysis by MALDI mass spectrometry}

MALDI mass spectrometry analyses were investigated in the same method with that of opium alkaloids as indicated above Section 2.

\subsubsection{Immunization and hybridization}

Immunization and hybridization were done in the same manner with that of opium alkaloids as indicated in Section 2 and previously communicated. 


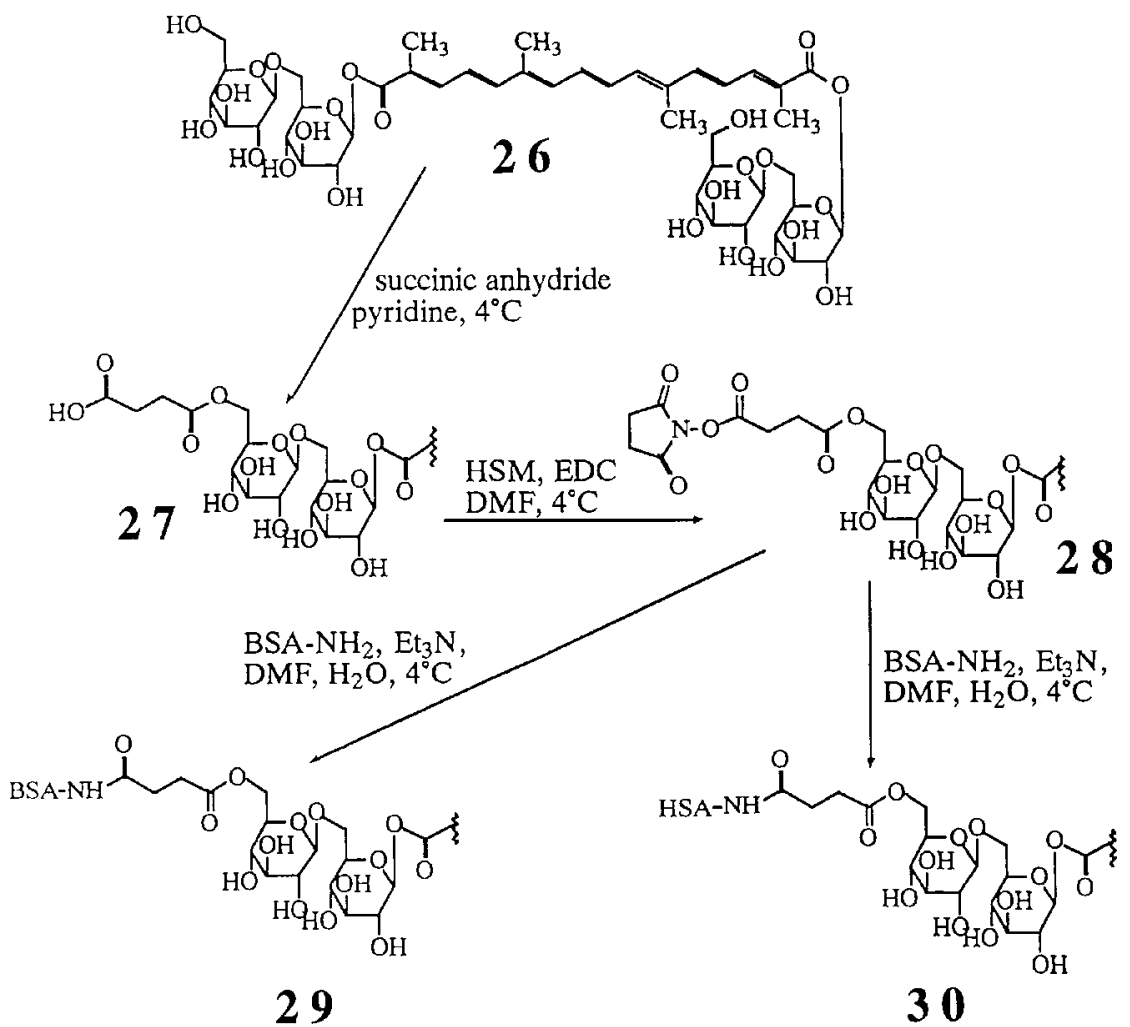

Fig. 11. Synthetic pathway of $\mathbf{2 9}, \mathbf{3 1}$.

\subsection{Results and discussions}

For the preparation of crocin-carrier protein conjugate we established two methods, using the succinate derivative (Fig. 11) as already indicated in the section of 7, and the preparation of conjugate between glucoside cleavaged by $\mathrm{NaIO}_{4}$ and carrier protein. The former method controls the position of hydroxyl group conjugated with succinic acid by the reaction condition resulting in that a hydroxyl group at C-6 position of two terminal glucoses is attacked by mild condition. On the other hand, unknown derivatization was induced in the later reaction because a random cleavage occurs by $\mathrm{NaIO}_{4}$ oxidation between two hydroxyl groups although the cis dihydroxyl position is cleavaged theoretically.

In order to determine the number of hapten in 29, a MALDI mass spectrometry was carried out. The mass spectrum of $\mathbf{2 9}$ is shown in Fig. 12. A broad peak coinciding with the antigen conjugate around at $m / z$ 75,647 appeared resulting in at least 8.6 molecules of $\mathbf{2 6}$ were conjugated. The singly, doubly, and triply ionized molecular ions of the intact conjugate that can be used for determination of the molecular weight of hapten conjugate were observed.

A broad peak $[\mathrm{M}+\mathrm{H}]^{+}$of crocin hemisuccinate-HSA conjugate (30) appeared at around $\mathrm{m} / z$ 98,342 in MALDI mass spectrometry (Fig. 13). From this molecular peak 30 molecules of 27 conjugated with HSA.

The crocin-HSA (31) synthesized via $\mathrm{NaIO}_{4}$ oxidation shows a sharp molecular peak around 69,504 (Fig. 14) compared to that of hemisuccinate preparation. The number of $\mathbf{2 6}$ combined with HSA was, however, smaller 3 molecules calculated from the molecular weight. 


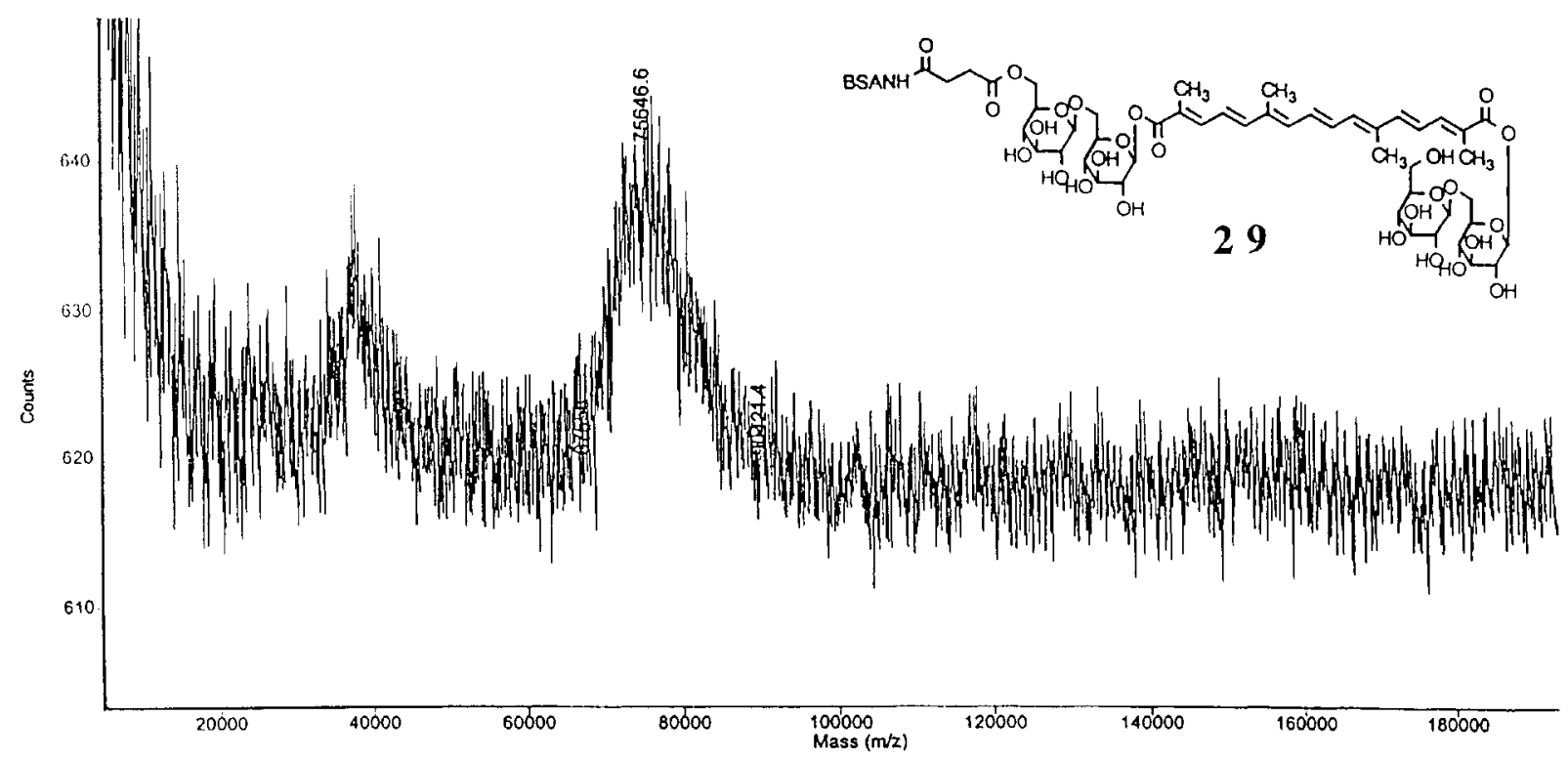

Fig. 12. MALDI mass spectrometry of 29.

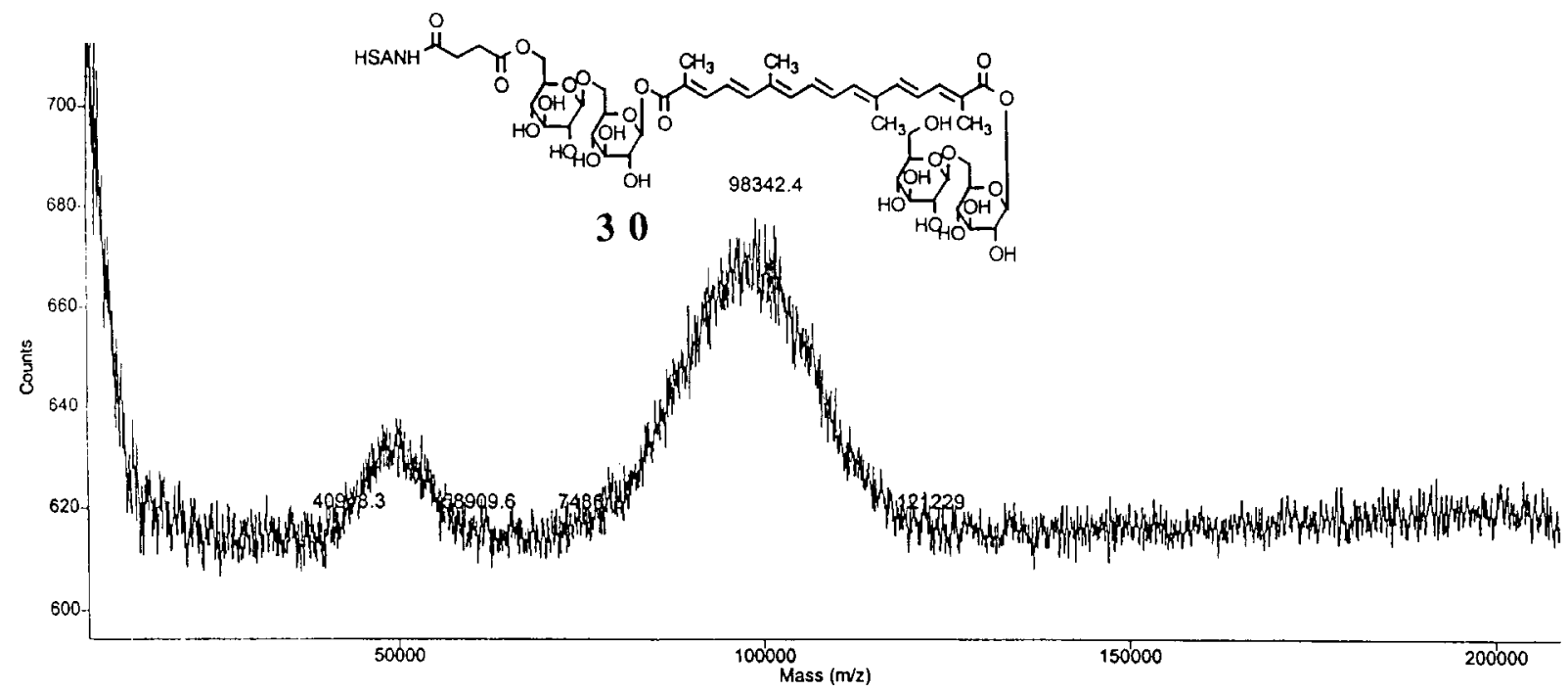

Fig. 13. MALDI mass spectrometry of $\mathbf{3 0}$.

The type of hapten-carrier protein is important for immunization. In the previous paper we established a new TLC-immunostaining method using anti-solamargine MAb originated from the preparation via $\mathrm{NaIO}_{4}$ oxidation cleavage [34]. In that case solasodine glucosides can be immunostained by anti-solamargine MAb and peroxidase labeled secondary antibody after transferred to PVDF membrane and treated with $\mathrm{NaIO}_{4}$ solution because the anti-solamargine $\mathrm{MAb}$ was prepared by immunization of solamargine-BSA conjugate prepared via $\mathrm{NaIO}_{4}$ oxidation. Immunization and hybridoma preparation using crocin-BSA conjugates synthesized by two methods have been investigated now. These results will be communicated elsewhere and compared both MAbs. 


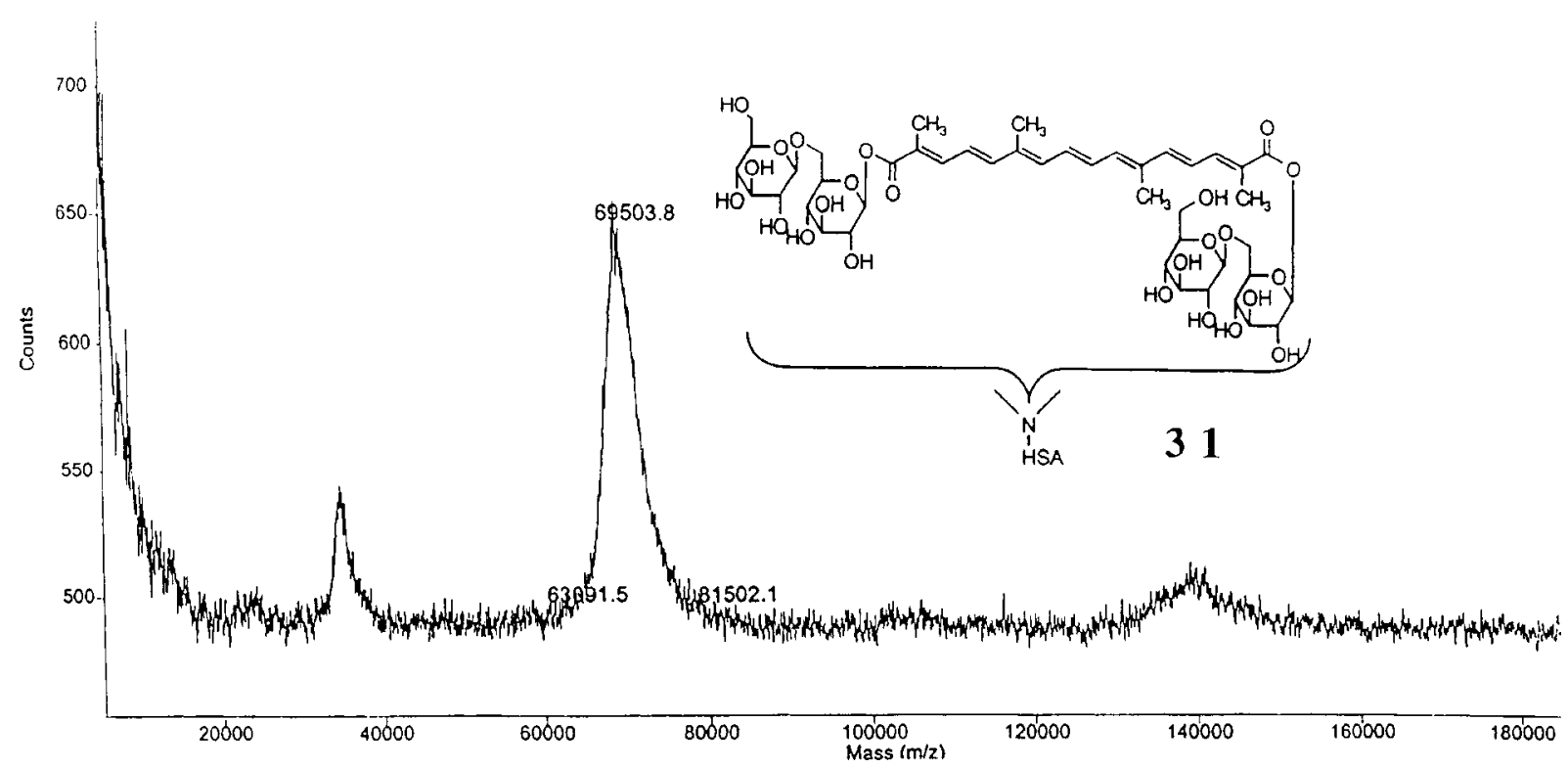

Fig. 14. MALDI mass spectrometry of $\mathbf{3 1}$ prepared via sodium periodate oxidation cleavage on sugar moiety.

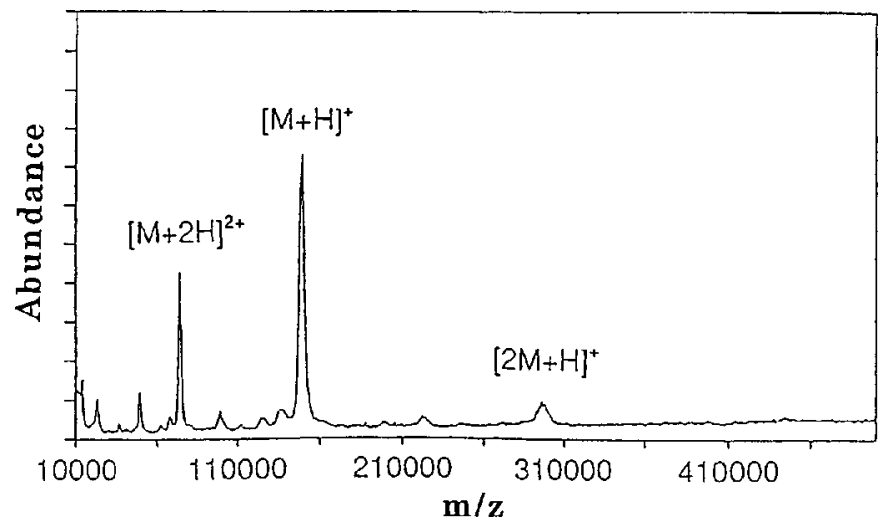

Fig. 15. MALDI mass spectrometry of purified $\operatorname{IgG}$ reactive to 7 .

\section{Analysis of MAbs against forskolin and cannabinoid by MALDI mass spectrometry}

Purified MAb (IgG) is required for the higher sensitive ELISA analysis. Therefore, the crude MAb cultured corresponding hybridoma in serum free medium has been purified by protein A affinity column chromatography.

Figure 15 shows the MALDI-mass spectrum of anti-forskolin MAb after the purification with protein A affinity column. The molecular weight was 148,600 in good agreement with that of human IgG being determined as 146,000 [35] in the spectrum. Since only minor molecular peaks were observed except from those related to $\operatorname{IgG}$, it became evident that the purification of $\operatorname{IgG}$ using protein A is good. Moreover, MALDI mass spectrometry can be used for the confirmation of purified MAbs instead of SDS-PAGE, HPLC and/or electric focusing analysis. 


\section{Conclusion}

Recently, the application of MALDI mass spectrometry has been expanded to various fields. Antigen conjugates for diterpenoid and steroidal alkaloid saponins have also been confirmed by MALDI mass spectrometry in our laboratory as review in the later section. Therefore, this strategy may be applied to many naturally occurring compounds and drugs, especially for these compounds having no specific UV absorbance, since difficulties and ambiguities remain in confirmation of antigen conjugate formation. Recently, it has been expanding that MALDI mass spectrometry can be available for the determination and the analysis of purity in the fields of higher molecular compounds like protein [36], immunoglobulin [37] and nucleotide [38]. Moreover, higher molecular compounds like polysaccharides, glucoproteins and proteins have attracted to interest as resources of new type of drugs due to their pharmacological and immunological activities such as anti-cancer, anti-complementary, reticuloendothelial system and hypoglycemic and so on. Moreover, enzyme immunoassay procedures using MAb have become an essential tool for biological studies on the naturally occurring biologically active compounds. For the formation of MAbs against low molecular compounds, the synthesis of hapten-carrier protein conjugates is necessary. In general the specificity of MAb depends on the site of linkage between the hapten and protein moieties, and the number of haptens in the immunogen conjugate. Therefore, antigen conjugates for diterpenoid; 7 [3], opium alkaloids [4]; $\mathbf{1}, \mathbf{2}$ and $\mathbf{3}$ and glycosides; solamargine [34] and $\mathbf{2 6}$ have been confirmed by MALDI mass spectrometry in our laboratory. This strategy may be applied to protein conjugates with various kinds of naturally occurring bioactive compounds and/or drugs, such as compounds having no specific UV absorbance, since difficulties and ambiguities remains in the confirmation of bioconjugate formation. Furthermore, this analytical methodology may expand to the complex of drugs having small molecule and proteins and/or peptides which have something biological function. In these studies it becomes clear that the use of appropriate protein as an internal standard in MALDI mass analysis provides us with a more accurate molecular ratio of hapten and carrier protein without the frequent errors.

It is difficult to determine the purity of higher molecular compounds by usual manner like SDS-PAGE or HPLC analyses exactly. Our results suggest that MALDI mass spectrometry can quickly determine the purity of MAb that molecular weight is 164,000 in high sensitivity, only p molar of samples is needed, and in high reproducibility, especially if used some appropriate internal standard. Moreover, the identification of protein is impossible without amino acid sequencing. However, since the exact molecular weight can be gained by MALDI mass spectrometry by using a small amount of sample, it makes possible to identify two protein samples.

\section{Acknowledgment}

We thank Prof. K. Oguri of Pharmaceutical Sciences, Kyushu University for providing thebaine. Thanks are due to Misses R. Sakata, Y. Shima and Y. Goto, and Mrs T. Fukada and H. Shinohara for their helps for preparations of hapten-carrier protein conjugates.

\section{References}

[1] E.W. Weiler, Chemistry of Plant Protection, Springer-Verlag, Berlin, 1990.

[2] I. Wangats, R.D. Schmit, S. Kreissig, C. Wittmann, B. Hock, A. Logendoh and F. Hillenkamp, Anal. Lett. 25 (1992), 1983.

[3] Y. Shoyama, R. Sakata, R. Isobe and H. Murakami, Org. Mass Spectr. 28 (1993), 987.

[4] Y. Shoyama, T. Fukada, T. Tanaka, A. Kusai and K. Nojima, Biol. Pharm. Bull. 16 (1993), 1051. 
[5] Y. Goto, Y. Shima, S. Morimoto and Y. Shoyama, Org. Mass Spectr. 29 (1994), 668.

[6] J.A. Glasel, W.M. Bradbury and R.F. Venn, Mol. Immunol. 20 (1983), 1419.

[7] J.A. Glasel and W.E. Myers, Life Sci. 36 (1985), 2523.

[8] J.A. Glasel and L.A. Pelosi, Biochem. Biophy. Res. Comm. 136 (1986), 1177.

[9] J. Sawada, N. Janejai, K. Nagamatsu and T. Terao, Mol. Immunol. 25 (1988), 937.

[10] A. Miller and J.A. Glasel, J. Mol. Biol. 209 (1989), 763.

[11] P.H. Kussie, J.M. Anchin, S. Subramaniam, J.A. Glasel and D.S. Linthicum, J. Immunol. 146 (1991), 4248

[12] J. Sawada, T. Yamazaki and T. Terao, Mol. Immunol. 30 (1993), 77.

[13] U. Wieczorek, N. Nagakura, C. Sund, S. Jendrzejewski and M.H. Zenk, Phytochemistry 25 (1986), 2639.

[14] Y. Shoyama, T. Fukada and H. Murakami, Cytotechnology 19 (1996), 55.

[15] S.V. Bhat, B.S. Bajwa, H. Dorneur and N.J. de Sousa, Tetrahedron Letters (1977), 1669.

[16] H. Metzger and E. Lindner, Drug Res. 31 (1981), 1248.

[17] T. Pfeuffer and H. Metzger, FEBS Lett. 146 (1982), 369.

[18] R. Sakata, Y. Shoyama and H. Murakami, Cytotechnology 16 (1994), 101.

[19] H. Yanagihara, R. Sakata, Y. Shoyama and H. Murakami, Planta Med. 62 (1996), 169.

[20] L.A. Matsuda, S.J. Lolait, M.J. Brownstein, A.C. Young and T.I. Bonner, Nature 346 (1990), 561.

[21] W.A. Devane, L. Hanus, A. Breuer, R.G. Pertwee, L.A. Stevenson, G. Griffin, D. Gibson, G.A. Mandelbaum, A. Etinger and R. Mechoulam, Science 258 (1992), 1946.

[22] Y. Shoyama, T. Yamauchi and I. Nishioka, Chem. Pharm. Bull. 18 (1970), 1327.

[23] A. Miyamoto, T. Yamamoto, M. Ohno, S. Watanabe, H. Tanaka, S. Morimoto and Y. Shoyama, Brain Res. 710 (1996), 234.

[24] H. Tanaka, R. Takahashi, S. Morimoto and Y. Shoyama, Plant Cell Rep. 15 (1996), 819.

[25] F. Taura, S. Morimoto and Y. Shoyama, J. Biol. Chem. 271 (1996), 17411.

[26] F. Taura, S. Morimoto, Y. Shoyama and R. Mechoulam, J. Am. Chem. Soc. 117 (1995), 9766.

[27] H. Tanaka, Y. Goto and Y. Shoyama, J. Immunoassay 17 (1996), 321.

[28] M. Sugiura, Y. Shoyama, H. Saito and N. Nishiyama, Proc. Japan Acad. 71 Ser.B (1995), 319.

[29] Y. Zhang, Y. Shoyama, M. Sugiura and H. Saito, Biol. Pharm. Bull. 17 (1994), 217.

[30] M. Sugiura, H. Saito, K. Abe and Y. Shoyama, Phytother. Res. 9 (1995), 100.

[31] M. Sugiura, Y. Shoyama, H. Saito and K. Abe, Jpn. J. Pharmacol. 67 (1995), 395.

[32] M. Sugiura, Y. Shoyama, H. Saito and K. Abe, J. Pharmacol. Exp. Therap. 271 (1994), 703.

[33] S. Morimoto, Y. Umezaki, Y. Shoyama, H. Saito, K. Nishi and N. Irino, Planta Med. 60 (1994), 438.

[34] H. Tanaka, W. Putalun, C. Tsuzaki and Y. Shoyama, FEBS Lett. 404 (1997), 279.

[35] J.J. Langone, J. Immunol. Met. 51 (1982), 33.

[36] S.L. Cohen and B.T. Chait, Anal. Chem. 68 (1966), 31.

[37] R.W. Neison, D. Dogruel and P. Williams, Mass Spectrom. 8 (1994), 627.

[38] B.A. Bruenner, T.T. Yip and T.W. Hutchens, Mass Spectrom. 10 (1996), 1797. 


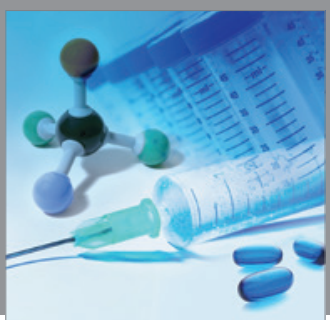

International Journal of

Medicinal Chemistry

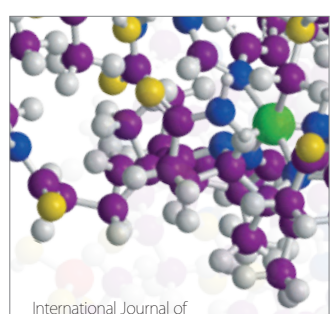

Carbohydrate Chemistry

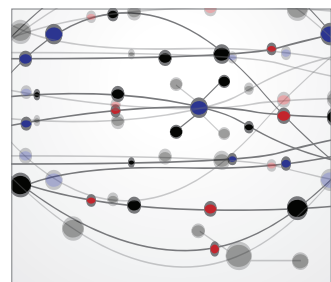

The Scientific World Journal
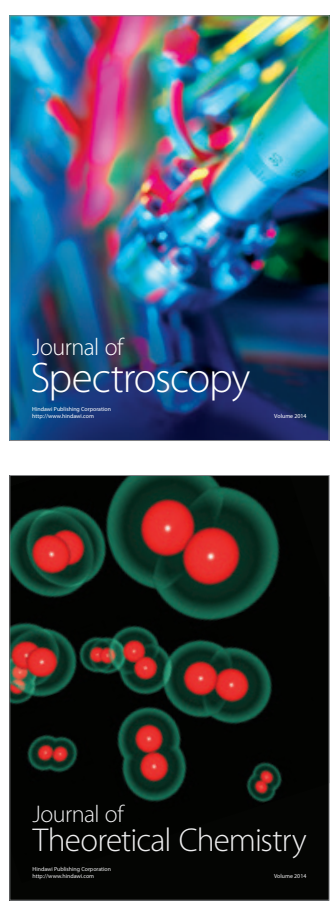
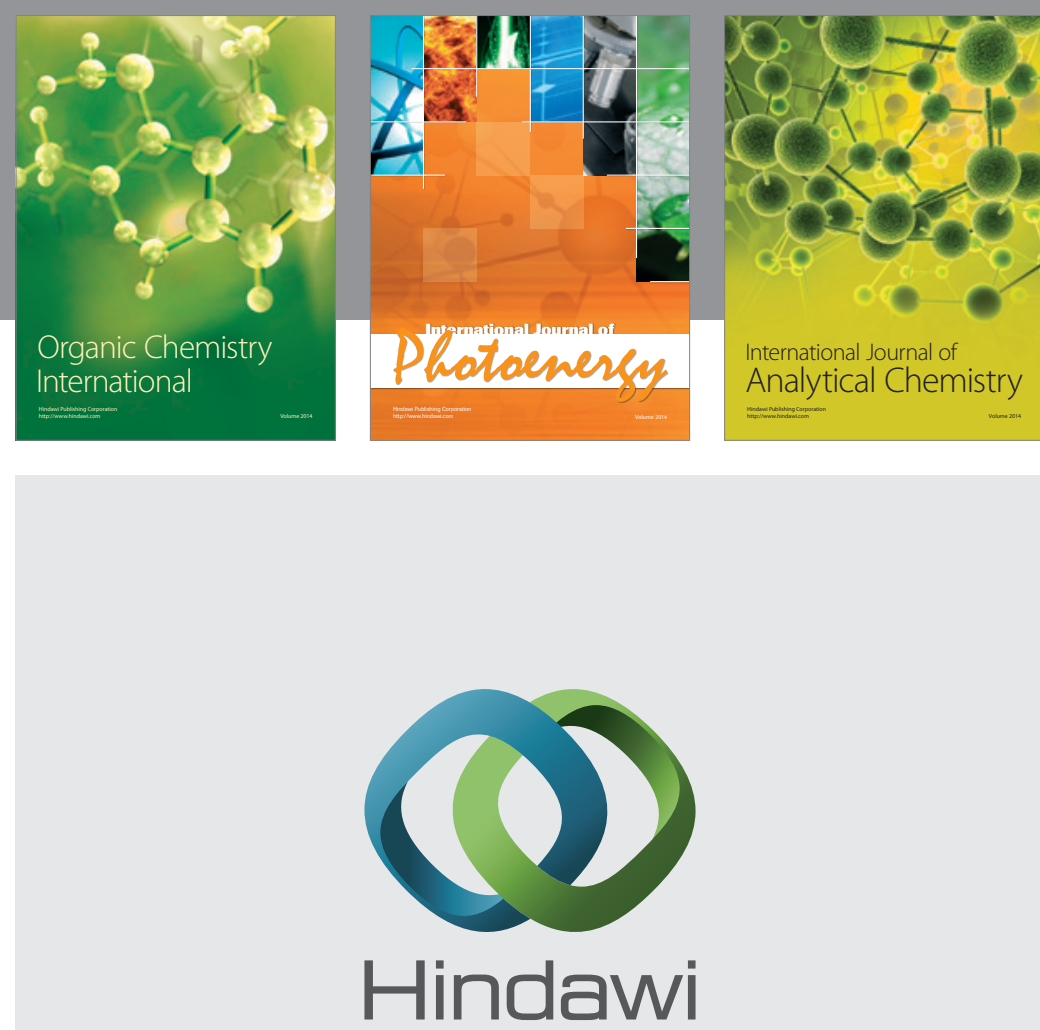

Submit your manuscripts at

http://www.hindawi.com
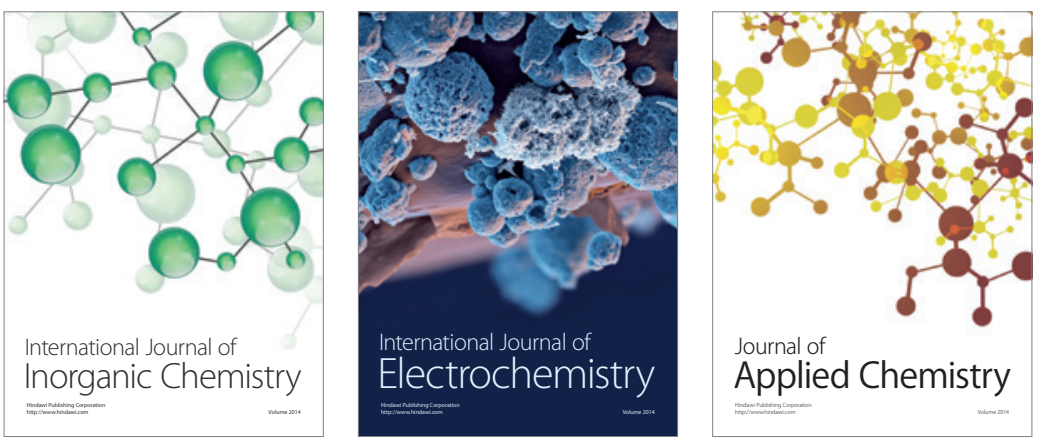

Journal of

Applied Chemistry
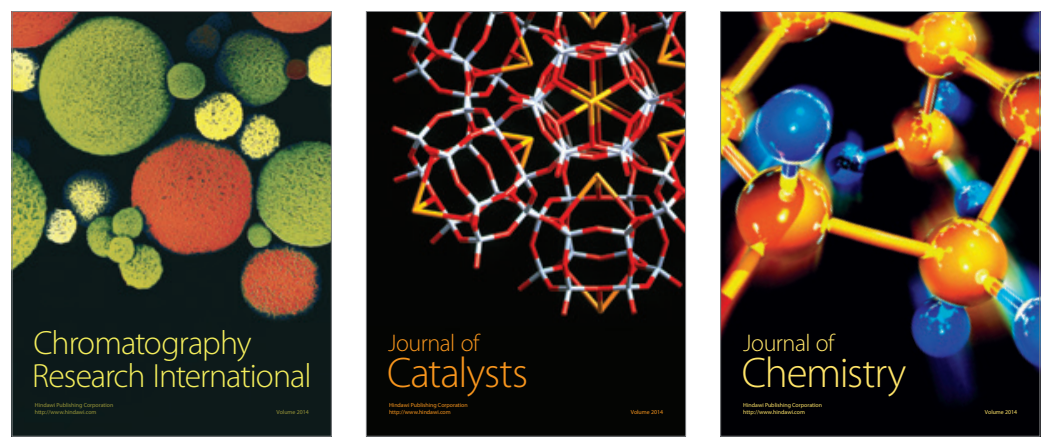
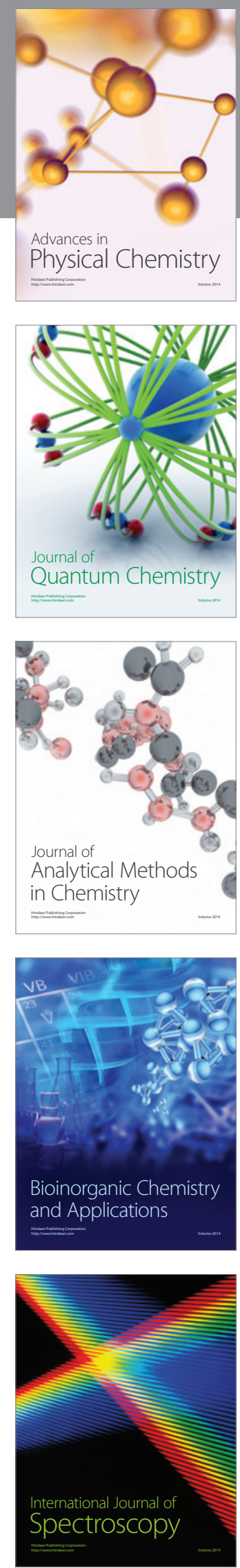